\title{
OBSERVATÓRIOS DE EDUCAÇÃO ESPECIAL: Políticas públicas, práticas e avaliação escolar
}

\author{
Márcia Denise Pletsch ${ }^{(*)}$ \\ Geovana Mendonça Lunardi Mendes \\ Regina Celia Linhares Hostins
}

Desde os anos de 1980, têm crescido e se disseminado pesquisas e publicações em periódicos e eventos científicos na área da educação especial, sobretudo a partir da ampliação da pós-graduação no país, da consolidação e criação de um grupo de trabalho em educação especial na Associação Nacional de Pós-Graduação e Pesquisa em Educação (Anped) e da Associação de Pesquisadores em Educação Especial (Abpee). Aumentou, também, o número de grupos e de linhas de pesquisa vinculados a esta temática na pós-graduação. Contudo, apesar dos avanços acadêmicocientíficos na área, essa ainda enfrenta desafios na produção do conhecimento coletivo e colaborativo.

Nesse sentido, nossa proposta, neste dossiê, é apresentar dados de pesquisas realizadas a partir de investigações colaborativas e coletivas, consolidadas a partir de 2006, notadamente com o Programa Observatório da Educação (Obeduc) da Coordenação de Aperfeiçoamento de Pessoal de Nível Superior (Capes). O referido Programa busca fomentar a pesquisa em Educação e financiar investigações que congreguem instituições, pesquisadores que atuam na pós-graduação, acadêmicos de doutorado, mestrado, graduação e professores da educação básica, os quais são subsidiados por meio de bolsas de pesquisa.

A proposta, entre outras, é fomentar a produção acadêmica e a formação de recursos humanos em educação, incentivando a articulação entre a pós-graduação, as licenciaturas e as escolas da rede pública da educação básica, a partir de pesquisas de campo e análise de dados do Instituo Nacional de Estudos e Pesquisas Educacionais Anísio Teixeira (Inep) (SILVEIRA, 2014).

\footnotetext{
${ }^{(*)}$ Márcia Denise Pletsch. Doutora em Educação. Professora do Programa de Pós-graduação em Educação, Contextos Contemporâneos e Demandas Populares (PPGEduc) da Universidade Federal Rural do Rio de Janeiro (UFRRJ). Jovem Cientista da Faperj e pesquisadora do CNPq. E-mail: marciadenisepletsch@gmail.com.

Geovana Mendonça Lunardi Mendes. Doutora em Educação. Professora do Programa de Pós-graduação em Educação e do Departamento de Pedagogia da Universidade do Estado de Santa Catarina (Udesc). E-mail: geolunardi@gmail.com.

Regina Celia Linhares Hostins. Doutora em Educação. Professora do Programa de Pós-graduação em Educação da Universidade do Vale do Itajaí (Univali). E-mail: reginalh@univali.br.
} 
Outra contribuição do Programa é o incentivo de pesquisas colaborativas em rede envolvendo diferentes universidades e escolas da rede pública de ensino. Investigações dessa natureza têm crescido e mostrado novas possibilidades de produção do conhecimento acerca dos processos educacionais.

É com base nessas premissas que apresentamos ao leitor um conjunto de artigos com resultados de pesquisas, financiadas pelo Obeduc/Capes, desenvolvidas em rede por pesquisadores de diferentes Universidades Brasileiras envolvendo temas que dialogam com a área de Educação Especial.

Estruturamos o dossiê em dois eixos temáticos, a saber: a) Redes de pesquisa, política educacional e escolarização; b) currículo e inclusão escolar.

No primeiro eixo unimos um conjunto de textos, os quais discutem as pesquisas em rede, associadas ao uso de diferentes metodologias, assim como as dimensões das políticas educacionais, notadamente a política de educação especial na perspectiva da educação inclusiva e as relações público-privado.

O texto de Mendes, Valadão e D’Affonseca apresenta a experiência e os desafios para desenvolver uma investigação em rede envolvendo mais de 200 pesquisadores por meio do Observatório Nacional de Educação Especial, que avaliou a implementação do Programa de Salas de Recursos Multifuncionais para a oferta do atendimento educacional especializado. Os resultados do Observatório Nacional em Educação Especial são, hoje, fundamentais para compreendermos não apenas o impacto da atual Política de Educação Especial na Perspectiva da Educação Inclusiva no que diz respeito aos processos avaliativos de alunos público alvo da Educação Especial, a estrutura de suporte especializado oferecido pelas redes de ensino por meio do Atendimento Educacional Especial (AEE) e as demandas postas para a formação de professores. Igualmente, é importante pela sua dimensão e amplitude, abrangendo a participação de 22 Universidades e 18 Programas de Pós-Graduação de 17 Estados brasileiros.

Os desdobramentos do Observatório Nacional de Educação Especial também são abordados por Jesus, Victor e Viera ao relatar o caso do Espírito Santo. A partir da metodologia pesquisaformação, os autores apresentam os resultados de sua experiência na formação de professores especializados que participaram das ações na Universidade Federal do Espirito Santo.

Laplane, Caiado e Kassar analisam as relações entre os setores públicos e privados na implementação de politicas na área de Educação Especial. As autoras trazem um conjunto de dados 
que revelam as proposições realizadas para garantir a presença histórica do setor privado na Educação Especial brasileira. Também, evidenciam os novos arranjos da iniciativa privada para permanecer e ampliar a sua participação na área, frente ao avanço das políticas de educação inclusiva na educação pública.

No segundo eixo unimos, um conjunto de textos que discutem questões candentes na fronteira entre a educação e a educação especial na perspectiva da inclusão escolar, com destaque para o currículo, a escolarização, e a aprendizagem de pessoas com deficiência, com ênfase na escolarização de alunos com deficiência intelectual.

O artigo de Silva apresenta uma análise de documentos para discutir o currículo em Educação Especial na perspectiva da educação inclusiva. A partir da análise de quatro documentos produzidos no período de 2006 a 2012, a autora discute diferentes aspectos, em especial, a flexibilização curricular.

O currículo também é discutido no texto de Pacheco, uma das contribuições internacionais que compõem o dossiê, apresentando os desafios impostos ao desenvolvimento curricular, quando tomamos por principio pedagógico a diversidade e a exclusão escolar.

O artigo de Mendes, Septimio e Neto apresenta um conjunto de reflexões decorrentes das pesquisas realizadas no abrigo de dois Observatórios da Educação, um com temática vinculada a Educação Especial e outro voltado as políticas de inserção de tecnologias, que nos fazem discutir o lugar e o sentido do "não saber" docente quando desafiados a construção de práticas inclusivas e inovadoras.

A escolarização e a aprendizagem de alunos com deficiência intelectual em contextos de inclusão escolar é objeto de estudo no artigo de Hostins, Silva e Alves. Valendo-se da teoria histórico-cultural e da análise de episódios de ensino na classe comum da escola inclusiva, as autoras articulam os conceitos de coletividade, colaboração e experiência, para pensar as práticas culturais de escolarização e a aprendizagem de alunos com deficiência intelectual.

Nessa mesma perspectiva teórica, Oliveira, Pletsch e Oliveira apresentam por meio de um estudo de caso realizado com um aluno do terceiro ano do ensino fundamental, o papel e as contribuições da avaliação mediada no processo de escolarização de pessoas com deficiência intelectual. As autoras discutem a partir da realização de atividades com o sujeito da participante da pesquisa dimensões que envolvem o desenvolvimento da memória, imaginação e da linguagem. 
O texto de Valentini, Gomes e Bisol identifica aspectos facilitadores para a inclusão de estudantes com deficiência intelectual em escolas comuns, a partir de revisão sistemática de 44 artigos publicados em periódicos científicos nacionais de 2008 a 2015. Aspectos como planejamento, adequação curricular, formação de professores, estrutura, investimentos, indicam caminhos que podem viabilizar mudanças no cotidiano das escolas para garantir melhores condições de escolarização dessa população.

A escolarização de alunos com deficiência no ensino comum e a sua relação com a ação docente é o foco do artigo de Correia e Baptista. Os autores a partir do pensamento sistêmico associado a uma pesquisa qualitativa do tipo bibliográfico analisam as produções científicas nacionais envolvendo práticas pedagógicas que favorecem a inclusão desses alunos.

O artigo final deste dossiê de autoria de Silva, Guarinello e Martins discute a inclusão no ensino superior, a partir de resultados de uma investigação sobre o papel do intérprete de Libras nesse contexto. $\mathrm{O}$ texto evidencia as dificuldades de atuação desse profissional no ensino superior, assim como indica possíveis caminhos e possibilidades de atuação no processo de acessibilidade dos surdos ao ensino superior.

A partir dessas considerações, entendemos que o presente dossiê, fruto das ações e das pesquisas desenvolvidas pelos grupos que constituem os diferentes projetos, contribui para a produção científica, visto que a constituição de redes colaborativas - áreas de conhecimento em uma relação intra e inter - articulam conhecimentos e processos de investigação nos campos da Educação e da Educação Especial.

É com esse espírito que esperamos contribuir com a discussão e a produção científica sobre os diferentes processos de escolarização de pessoas com deficiência com vistas a ampliação dos direitos educacionais dessa população, bem como com a formação docente e os diferentes modos de ser escola.

\section{REFERÊNCIA}

SILVEIRA, Helder Eterno. O programa Observatório da Educação na Capes: alguns dados e compreensões. In: FIGUEIREDO, Sérgio José Soares (Org.). A formação do professor de música no Brasil. 1a.ed. Belo Horizonte: Fino Traço, 2014, p. 15-32.

Submetido abril 2016

Aprovado jun. 2016 